\title{
Laparoscopic versus Open Inguinal Hernia Repair: A Systematic Review
}

\author{
KHALED M.A. HOSNY, M.D.; AMR H. AFIFY, M.D. and EMAN K.Y. EL GARAN, M.Sc. \\ The Department of General Surgery, Faculty of Medicine, Ain Shams University
}

\begin{abstract}
Background: Inguinal hernia repair is the most frequently performed operation in general surgery. However, the question about the most appropriate technique still confuses the community of surgeons. The standard method for inguinal hernia repair had changed little over a hundred years until the introduction of synthetic mesh. This mesh can be placed by either using an open approach or by using a minimal access laparoscopic technique.
\end{abstract}

Aim of Work: The purpose of this review was to compare laparoscopic techniques with open mesh technique for inguinal hernia repair.

Material and Methods: All published randomized and non randomized controlled trial, meta-analysis, case-control trial \& NICE guidelines comparing laparoscopic inguinal hernia repair with open inguinal hernia repair were eligible for inclusion. All published trials between 1994 to 2019. Trials were included only published in English. All data collected in 2018 to 2020. Participants were adults diagnosed with inguinal hernia either males or females. The following data items were sought for all trials: Duration of operation (min), vascular injury, visceral injury, length of hospital stay (days), time to return to usual activities (days), time to return to work ( days), post-operative pain, chronic persisting inguinal pain ( defined as inguinal pain of any severity as near 12 months after the operation as possible provided this was at least after 3 months), hernia recurrence, cost effectiveness, learning curve, quality of life.

Results: Overall, recurrence rates were higher among patients whose hernias were repaired by the laparoscopic technique $(3.6 \%)$ compared to open group $(1.9 \%)(p<0.001)$. In five studies concerning the treatment of recurrent hernias, the recurrence rate varies between $0.4 \%$ and $8.3 \%$ for laparoscopic techniques and between $1 \%$ and $15.6 \%$ for the Lichtenstein procedure. However, the recurrence rate differs greatly between hospitals and individual surgeons, especially for those that perform laparoscopic procedures. For those that have passed an educational program with specific regard to laparoscopy, the recurrence rate is low. Open mesh repair is economical, easy to teach and learn without any steep learning

Correspondence to: Dr. Khaled M.A. Hosny,

The Department of General Surgery, Faculty of Medicine, Ain Shams University curve. Open hernia repair does not need any specialized training and results are same in both specialist and nonspecialist center. Open hernia repair does not carry any risk of serious visceral or bowel injuries.

Conclusion: Laparoscopic hernia repair is more costly; difficult to learn with a steep learning curve, our results provide evidence that after a laparoscopic repair return to usual activity is faster and persisting pain is reduced. However, operation times are longer and there appears to be a higher rate of serious complication rate in respect of visceral and vascular injuries. The complication rate reduces as the surgeons become more experienced in this procedure comparable with that of open repair. Laparoscopic repair is associated with less post-operative morbidity and faster recovery and satisfaction as documented by less post-operative pain, earlier mobilization and discharge from the hospital, as well as early return to work.

Key Words: Laparoscopic-Open inguinal hernia repair.

\section{Introduction}

A HERNIA is defined as a protrusion or projection ( prolapse) of an organ through the wall of the cavity where it is normally contained. There are many types of hernia, mostly classified according to the physical location, with the abdominal wall being the most susceptible site. Specifically, reports show that the most frequently seen hernia is the inguinal hernia (70-75\% of cases), followed by femoral (6-17\%) and umbilical (3-8.5\%) hernias. Hernias are also found in other sites such as the ventral or epigastric hernia, located between the chest cavity and the umbilicus [1].

Hernias can be uncomfortable and are sometimes accompanied by severe pain, which worsens during bowel movements, urination, heavy lifting, or straining. Occasionally, a hernia can become strangulated, which occurs when the protruding tissue swells and becomes incarcerated. Strangulation will interrupt blood supply and can lead to 
infection, necrosis, and potentially life-threatening conditions $[2,3]$.

Hernia formation is a multifactorial process involving endogenous factors including age, gender, anatomic variations, and inheritance and exogenous factors such as smoking, comorbidity, and surgical factors. However, these factors alone do not explain why some develop abdominal wall hernias [4].

Already in 1924, the anatomist Sir Arthur Keith proposed that surgeons should try to perceive tendons and fascia as living structures in order to understand the hernia disease properly. Research on synthesis and breakdown of connective tissue in relation to pathophysiological mechanisms of hernia formation is important to comprehend herniogenesis and to select a proper treatment strategy for the individual patient [5].

Some patients seem to be especially susceptible to hernia development [6]. Patients operated on for abdominal aortic aneurysms have a higher risk of developing an incisional hernia postoperatively as opposed to patients operated on for aortoiliac occlusive disease [7]. Patients with rare connective tissue disorders such as Marfan's syndrome and Ehlers-Danlos syndrome have an earlier onset and a higher risk of hernia development. Further, patients with direct inguinal, bilateral inguinal, or recurrent inguinal hernia are at higher risk of ventral hernia formation, suggesting a systemic predisposition to hernia formation [5].

Emerging evidence suggests that inguinal hernias represent an inherited disease; however the inheritance pattern remains to be clarified. There is increased risk of developing an inguinal hernia, if a first-degree relative has a history of inguinalhernia repair [8].

Studies on the morphology of the fascial tissue surrounding inguinal hernias found lower total collagen content in patients with inguinal hernias compared with individuals without inguinal hernia. Furthermore, the fascial collagen architecture appears altered as described histologically by an uneven distribution of collagen fibers, thinner collagen fibers, inflammation, and degeneration of muscle fibers. The collagen quality seems to be more important than the collagen quantity. In fascia from hernia patients, there is less type I collagen relative to type III collagen resulting in a decreased type I to III collagen ratio and thinner collagen fibers with less tensile strength. These alterations are also present at the mRNA level suggesting that the problem appears during collagen synthesis. A decreased type I to III collagen ratio is also present in skin biopsies from hernia patients, suggesting that the connective tissue alterations are systemic $[9,10]$.

The reason for the altered collagen quality and the decreased type I to III ratio remains to be clarified. It has been suggested that altered activity levels of the enzymes involved in the collagen synthesis and maturation process may play a role. Decreased activity of lysyloxidase results in decreased cross-linking of collagen fibrils, which is essential for collagen strength and stability. In addition, recent studies found systemically decreased turnover of type V collagen both in patients with inguinal hernia and in patients with incisional hernia. Type $\mathrm{V}$ collagen is necessary for initiation of collagen fibril formation, and decreased levels of type $\mathrm{V}$ collagen may thereby impair the collagen synthesis $[\mathbf{1 1 , 1 2}]$.

Overall, the collagen alterations found in patients with inguinal hernias are more pronounced in patients with direct hernias as opposed to patients with indirect hernias, suggesting that an imbalance in collagen turnover is especially important in the formation of direct hernias [13].

\section{Aim of the work:}

The purpose of this review was to compare laparoscopic techniques with open mesh technique for inguinal hernia repair.

\section{Material and Methods}

Criteria for considering studies for this review: Types of studies:

All published randomized and non randomized controlled trial, meta-analysis, case-control trial \& NICE guidelines comparing laparoscopic inguinal hernia repair with open inguinal hernia repair were eligible for inclusion. Trials were included only published in English.

\section{Types of participants:}

Participants were adults diagnosed with inguinal hernia either males or females.

\section{Types of interventions:}

\section{Methods of surgical repair of inguinal hernia:}

A- Laparoscopic inguinal hernioplasty using mesh [ including the Trans-Abdominal Pre-Peritoneal technique (TAPP) and the Totally Extra Peritoneal technique (TEP)].

B- Open mesh repair using tension free hernioplasty. 


\section{Types of outcome measures:}

The following data items were sought for all trials: Duration of operation (min), vascular injury, visceral injury, length of hospital stay (days), time to return to usual activities (days), time to return to work (days), post-operative pain, chronic persisting inguinal pain (defined as inguinal pain of any severity as near 12 months after the operation as possible provided this was at least after 3 months), hernia recurrence, cost effectiveness, learning curve, quality of life.

\section{Search strategy for identification of studies:}

We have been conducted electronic searches in PubMed, Google Scholar and the Cochrane Central Controlled Trials Registry to identify relevant articles. For this review, the register was searched using the terms: Inguinal hernia, laparooscopic inguinal hernia repair, Lichtenstein hernia repair, TEP and TAPP techniques for laparoscopic hernia, tention free hernioplasty". Review articles and bibliographies of each randomized controlled trial identified have been searched for additional references that may contain further randomized controlled trials.

\section{Methods of the review:}

Locating and selecting studies:

Abstracts of articles identified using the search strategy above have been viewed, and articles that appear to fulfill the inclusion criteria were retrieved in full. Data on at least one of the outcome measures must be included in the study. Each article identified was reviewed and categorized into one of the following groups:

\section{Inclusion criteria:}

- Published randomized and non randomized controlled trial, meta-analysis \& NICE guidelines comparing laparoscopic inguinal hernia repair with open inguinal hernia repair.

- Studies with patient diagnosed as primary or recurrent inguinal hernia.

\section{Exclusion criteria:}

- Studies which compare laparoscopic mesh repair and open tissue repair, because there would be superiority of lap mesh repair in the form of low recurrence rate by virtue of placement of mesh.

- Studies included patients with irreducible or strangulated hernia.

- Studies which compare laparoscopic mesh repair and open mesh repair in elderly.

- Studies which compare laparoscopic repair and open repair in children.
Available literature has been analyzed with regards to: Recurrence rate, complications, operating time, cost effectiveness, post-operative pain, length of hospital stay and return to work and activity. When there was a doubt, a second reviewer assessed the article and a consensus was reached.

\section{Data extraction:}

Data was independently extracted by two reviewers and cross-checked.

\section{Results}

There were 30 eligible trials included in this review. All trials were restricted to elective inguinal hernia repair. 12 included recurrent as well as primary hernias, 5 were limited to primary hernias only, 5 included recurrent hernias only, and these details were not reported for eight studies. The comparisons in the 30 trials were: TAPP versus open in 9 trials, TEP versus open in 11 trials, mixture of laparoscopic versus open in 10 trials.

Studies comparing open to laparoscopic repair of inguinal hernia:

Table (1): Studies comparing operating time.

\begin{tabular}{|c|c|c|c|c|}
\hline \multirow{3}{*}{ Studies } & \multicolumn{4}{|c|}{ Operative time (min) } \\
\hline & \multicolumn{2}{|r|}{ Open } & \multicolumn{2}{|c|}{ Laparoscopic } \\
\hline & No. & Mean & No. & Mean \\
\hline - Murthy and & 30 & 43.5 & 20 & 92.25 \\
\hline $\begin{array}{l}\text { Ravalia, } 2018 \\
\text { - Bringman et al., } \\
2003\end{array}$ & 95 & 45 & 90 & 50 \\
\hline $\begin{array}{l}\text { - Andersson et al., } \\
2003\end{array}$ & 87 & 59 & 81 & 81 \\
\hline $\begin{array}{l}\text { - Pawanindra Lal et } \\
\text { al., } 2003\end{array}$ & 25 & 54 & 25 & 75.72 \\
\hline $\begin{array}{l}\text { - Vidovic et al., } \\
2007\end{array}$ & 233 & 58.2 & 112 & 58.6 \\
\hline $\begin{array}{l}\text { MRC Trial group, } \\
1999\end{array}$ & 453 & 43.3 & 462 & 58.4 \\
\hline $\begin{array}{l}\text { - Picchio et al., } \\
1999\end{array}$ & 52 & 33.9 & 53 & 49.6 \\
\hline $\begin{array}{l}\text { - G. L. Beets et al., } \\
1999\end{array}$ & 37 & 56 & 42 & 79 \\
\hline - Wright et al., 1996 & 64 & 43.5 & 67 & 62.5 \\
\hline - Stoker et al., 1994 & 66 & 35 & 67 & 53.5 \\
\hline Total & 1142 & $48.49 \pm 8.61$ & 1019 & $\begin{array}{c}66.06 \pm 14 . \\
85\end{array}$ \\
\hline Independent $t$-test & \multicolumn{4}{|c|}{33.342} \\
\hline$p$-value & \multicolumn{4}{|c|}{$<0.001$ (HS) } \\
\hline
\end{tabular}


Table (2): Studies comparing recurrence in laparoscopic versus open mesh repair.

\begin{tabular}{|c|c|c|c|c|c|c|}
\hline \multirow{3}{*}{ Studies } & \multicolumn{4}{|c|}{ Recurrence } & \multirow{3}{*}{$\begin{array}{c}\text { Test } \\
\text { value }\end{array}$} & \multirow{3}{*}{$\begin{array}{c}p- \\
\text { value }\end{array}$} \\
\hline & \multicolumn{2}{|r|}{ Open } & \multicolumn{2}{|c|}{ Laparoscopic } & & \\
\hline & No. & No. (\%) & No. & No. $(\%)$ & & \\
\hline Ramsay et al., 2019 & 78445 & $1397(1.8 \%)$ & 10145 & $362(3.6 \%)$ & 147.47 & $<0.001$ \\
\hline Myers et al., 2010 & 90 & $2(2.2 \%)$ & 90 & $3 \quad(3.3 \%)$ & 0.206 & 0.650 \\
\hline McCormack K et al., 2003 & 3504 & $109(3.1 \%)$ & 3138 & $86(2.7 \%)$ & 0.796 & 0.372 \\
\hline Hallan et al., 2008 & 87 & $4(4.6 \%)$ & 81 & $3(3.7 \%)$ & 0.084 & 0.772 \\
\hline NICE, 2004 & 2064 & $35(1.7 \%)$ & 2059 & $49(2.4 \%)$ & 2.417 & 0.120 \\
\hline Neumavar, 2004 & 834 & $41(4.9 \%)$ & 862 & $87(10.1 \%)$ & 16.28 & $<0.001$ \\
\hline Anderson, 2003 & 87 & $0(0.0 \%)$ & 81 & $2(2.5 \%)$ & 2.174 & 0.140 \\
\hline Douek M et al., 2003 & 120 & $3(2.5 \%)$ & 122 & $2(1.6 \%)$ & 0.221 & 0.638 \\
\hline MRC Lap Groin Hernia Trial group, 1999 & 349 & $0(0.0 \%)$ & 362 & $7(1.9 \%)$ & 6.816 & 0.009 \\
\hline Champault, 1997 & 49 & $1(2 \%)$ & 51 & $3(5.9 \%)$ & 2.862 & 0.091 \\
\hline G.L. Beets et al., 1999 & 52 & $1(1.9 \%)$ & 56 & $7(12.5 \%)$ & 4.398 & 0.036 \\
\hline Dedemadiet al., 2006 & 32 & $2(6.3 \%)$ & 50 & $1(2.0 \%)$ & 1.000 & 0.317 \\
\hline Demetrashvili et al., 2011 & 28 & $0(0.0 \%)$ & 24 & $0(0.0 \%)$ & 0.000 & 1.000 \\
\hline Eklund et al., 2007 & 74 & $12(16.2 \%)$ & 73 & $12(16.4 \%)$ & 0.001 & 0.975 \\
\hline Kouhia et al., 2009 & 47 & $3(6.4 \%)$ & 49 & $0 \quad(0.0 \%)$ & 3.229 & 0.072 \\
\hline Kumar et al., 1999 & 25 & $2(8.0 \%)$ & 25 & $1(4.0 \%)$ & 0.355 & 0.551 \\
\hline Total & 85932 & $1612(1.9 \%)$ & 17268 & $625(3.6 \%)$ & 206.109 & $<0.001$ \\
\hline
\end{tabular}

Table (3): Studies comparing complications between laparoscopic and open mesh repair of Inguinal Hernia.

\begin{tabular}{|c|c|c|c|c|c|c|}
\hline \multirow{3}{*}{ Studies } & \multicolumn{4}{|c|}{ Complications } & \multirow{3}{*}{$\begin{array}{c}\text { rest } \\
\text { value }\end{array}$} & \multirow{3}{*}{$\begin{array}{c}p- \\
\text { value }\end{array}$} \\
\hline & \multicolumn{2}{|r|}{ Open } & \multicolumn{2}{|c|}{ Laparoscopic } & & \\
\hline & No. & No. $(\%)$ & No. & No. $(\%)$ & & \\
\hline McCormack et al., 2003 & 5357 & $6(0.1 \%)$ & 4813 & $15(0.3 \%)$ & 4.904 & 0.027 \\
\hline Vidovic et al., 2007 & 233 & $1(0.4 \%)$ & 112 & $2(1.8 \%)$ & 1.615 & 0.204 \\
\hline Neumayar, 2004 & 994 & $1(0.1 \%)$ & 989 & $10(1.0 \%)$ & 7.450 & 0.006 \\
\hline MRC Lap Groin Hernia Trial group, 1999 & 453 & $6(1.3 \%)$ & 462 & $25(5.4 \%)$ & 11.671 & 0.001 \\
\hline Total & 7037 & $14(0.2 \%)$ & 6376 & $52(0.8 \%)$ & 25.975 & $<0.001$ \\
\hline
\end{tabular}

Table (4): Studies comparing time to return to usual activities between laparoscopic and open mesh repair of Inguinal Hernia.

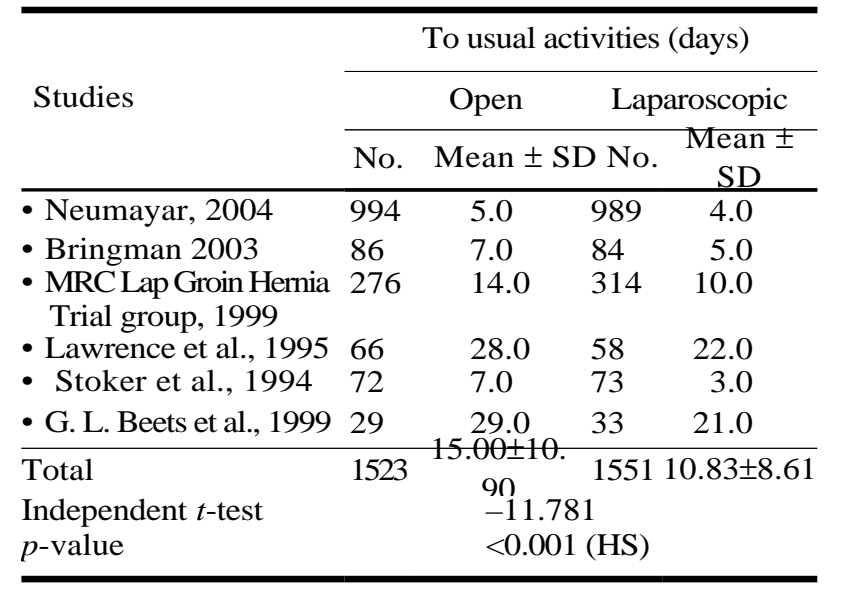

$p$-value $>0.05$ : Non Significant $(\mathrm{NS})$

$p$-value $<0.05$ : Significant $(\mathrm{S})$

$p$-value <0.01: Highly Significant (HS)

$\bullet:$ Independent $t$-test.
Table (5): Studies comparing time to return to work between laparoscopic and open mesh repair of Inguinal Hernia.

\begin{tabular}{|c|c|c|c|c|}
\hline \multirow{3}{*}{ Studies } & \multicolumn{4}{|c|}{ Return to work (days) } \\
\hline & \multicolumn{2}{|r|}{ Open } & \multicolumn{2}{|c|}{ Laparoscopic } \\
\hline & No. & Mean \pm SD & No. & $\begin{array}{l}\text { Mean } \pm \\
\text { SD }\end{array}$ \\
\hline $\begin{array}{l}\text { - Pawanindra Lal et } \\
\text { al., } 2003\end{array}$ & 25 & $19.30 \pm 4.30$ & 25 & $12.8 \pm 7.1$ \\
\hline - Anderson, 2003 & 81 & $11.00 \pm 8.00$ & 75 & $8.0 Q+5.00$ \\
\hline - Stoker et al., 1994 & 39 & $28.00 \pm 0.00$ & 40 & \\
\hline $\begin{array}{l}\text { - G. L. Beets et al., } \\
1999\end{array}$ & 16 & $23.00 \pm 12.4$ & 16 & $13.00 \pm 8.2$ \\
\hline Total & 161 & $20.33 \pm 7.17$ & 156 & $11.95 \pm 2$. \\
\hline Independent $t$-test & \multicolumn{4}{|c|}{-13.693} \\
\hline$p$-value & \multicolumn{4}{|c|}{$<0.001(\mathrm{HS})$} \\
\hline
\end{tabular}

$p$-value $>0.05$ : Non Significant (NS).

$p$-value $<0.05$ : Significant (S).

$p$-value <0.01: Highly Significant (HS).

$\bullet:$ Independent $t$-test. 
Table (6): Studies comparing chronic persisting inguinal pain between laparoscopic and open mesh repair of Inguinal Hernia.

\begin{tabular}{|c|c|c|c|c|c|c|}
\hline \multirow{3}{*}{ Studies } & \multicolumn{4}{|c|}{ Chronic persisting pain } & \multirow{3}{*}{$\begin{array}{c}\text { Test } \\
\text { value }\end{array}$} & \multirow{3}{*}{$\begin{array}{c}p- \\
\text { value }\end{array}$} \\
\hline & \multicolumn{2}{|r|}{ Open } & \multicolumn{2}{|c|}{ Laparoscopic } & & \\
\hline & No. & No. $(\%)$ & No. & No. $(\%)$ & & \\
\hline Myers et al., 2010 & 90 & $9(10.0 \%)$ & 90 & $3(3.3 \%)$ & 3.214 & 0.073 \\
\hline Hallan et al., 2008 & 81 & $11(13.6 \%)$ & 73 & $6(8.2 \%)$ & 1.124 & 0.289 \\
\hline M Douek et al., 2003 & 120 & $12(10.0 \%)$ & 122 & $2(1.6 \%)$ & 7.758 & 0.005 \\
\hline MRC Lap Groin Hernia Trial group, 1999 & 362 & $133(36.7 \%)$ & 394 & $113(28.7 \%)$ & 5.583 & 0.018 \\
\hline Dedemadi et al., 2006 & 32 & $2 \quad(6.3 \%)$ & 50 & $2(4.0 \%)$ & 0.213 & 0.644 \\
\hline Demetrashvili et al., 2011 & 28 & $12(42.9 \%)$ & 24 & $4(16.7 \%)$ & 4.161 & 0.041 \\
\hline Eklundet al., 2007 & 74 & $1(1.4 \%)$ & 73 & $1(1.4 \%)$ & 0.000 & 1.000 \\
\hline Kouhiaet al., 2009 & 47 & $13(27.7 \%)$ & 49 & $4(8.2 \%)$ & 6.257 & 0.012 \\
\hline Total & 834 & $193(23.1 \%)$ & 875 & $135(15.4 \%)$ & 16.379 & $<0.001$ \\
\hline
\end{tabular}

Table (7): Studies comparing Cost of laparoscopic and open mesh repair of Inguinal Hernia.

\begin{tabular}{lll}
\hline Studies & \multicolumn{2}{c}{ Cost comparison } \\
\cline { 2 - 3 } & Open & Laparoscopic \\
\hline Jacobs et al., 2008 & 117 USD & 237 USD 4757 USD 314 \\
Anderson, 2003 & 4408 USD & more pounds than open \\
MRC Trial group, 1999 & & 7063 SEK \\
Jhoansson et al., 1999 & 417 SEK & 746.87 USD \\
Wellwood et al., 1998 & 412.27 USD & 1239 USD \\
Heikkine et al., 1998 & 782 USD & 716 USD \\
G. L. Beets et al., 1999 & 566 USD & 850 \\
Lawrence et al., 1995 & 269 & \\
& & \\
\hline
\end{tabular}

Table (8): Studies discussing learning curve of laparoscopic and open mesh repair of Inguinal Hernia.

\begin{tabular}{|c|c|}
\hline \multirow[t]{2}{*}{ Studies } & Learning curve \\
\hline & Laparoscopic \\
\hline $\begin{array}{l}\text { - Merola et } \\
\text { al., } 2019\end{array}$ & $\begin{array}{l}\text { - } 100 \text { Lichtenstein procedures performed by } 4 \text { trainees from three different institutions and compared them with } \\
\text { the same number of procedures performed by } 3 \text { senior surgeons from the same institutions. No differences about } \\
\text { biometrical features were found between the seven groups of patients. Analysis showed that the trainees } \\
\text { achieve the learning curve after } 37-42 \text { procedures, reaching an operative time similar to that one of the senior } \\
\text { surgeons. }\end{array}$ \\
\hline $\begin{array}{l}\text { et al., } \\
2004\end{array}$ & $\begin{array}{l}\text { - The recurrence rate associated with laparoscopic repair was greater than } 10 \text { percent for the } 58 \text { urgeons who } \\
\text { reported having performed } 250 \text { or fewer laparoscopic repairs in any category, whereas the recurrence rate was } \\
\text { less than } 5 \text { percent for the } 20 \text { surgeons who reported having performed more than } 250 \text { laparoscopic repairs }(p \\
<0.001 \text { for the comparison of this category to all other categories). For open repairs, there was no significant } \\
\text { difference in the rate of recurrence between the most experienced group of surgeons (those who had performed } \\
\text { more than } 250 \text { renairs) and surgenns with less exnerience. }\end{array}$ \\
\hline
\end{tabular}

\section{Discussion}

Laparoscopic inguinal hernia repair takes longer than open mesh repair $(p<0.001)$. In technology appraisal guidance 83 by National Institute for clinical excellence, Sept. 2004, it was stated that laparoscopic surgery was associated with a statistically significant increase in operation time compared with open methods of hernia repair. Metaanalysis of 16 randomized control trials of Trans
Abdominal Pre Peritoneal (TAPP) repair demonstrated on overall increase of 13.33 minutes compared with open repair. Meta-analysis of eight randomized control trial of Trans Extra-Peritoneal ( TEP) repair demonstrated an overall increase of 7. 89 minutes compared with open repair [14].

Memon and colleagues reviewed the data from 29 published randomized clinical trials and concluded that patients who underwent laparoscopic 
repair of inguinal hernia took longer time for surgery [15]. In a Bringman trial operating time was found to be 5 minutes shorter in open mesh repair in comparison to laparoscopic group [16].

In a non-randomized comparative study by Murthy and Ravalia, the mean operating time in laparoscopic group was 92.25 minutes while in the open repair group was 43.5 minutes, which is significantly supplementary $(p \leq 0.05)$ [17].

With regard to operation length, most evidence in the literature points to a shorter operation duration with open repair [18]. The 2003 Cochrane Database Systematic Review demonstrated that the duration of operation was longer in the laparoscopic groups [19]. A meta-analysis in the British Journal of Surgery described a similar increase of $15.2 \mathrm{~min}$ with laparoscopic inguinal hernia repair [ 15]. The difference in the duration of the operation can be partly attributed to operative complications, which although uncommon for both methods, were more frequent in the laparoscopic group for visceral and vascular injuries [20].

Overall, recurrence rates were higher among patients whose hernias were repaired by the laparoscopic technique (3.6\%) compared to open group ( $1.9 \%)(p<0.001)$.

An ideal approach to hernia repairs should have a low recurrence rate [14]. The frequency of hernia recurrence depends on a number of factors including the type of hernia repair initially performed, the co-morbidities of the patient and the length of time from the original hernia repair [ 19].

The largest reviews of inguinal hernia repairs suggest no apparent difference in recurrence between laparoscopic and open mesh methods of hernia repair [20].

Kavic in his critical review, (2013), reported a separate meta-analysis published in the British Journal of Surgery in 2000 reported similar findings in that overall recurrences did not differ between the laparoscopic and open groups [19].

There is, however, some evidence in the literature demonstrating increased recurrences with laparoscopic repair. In 2004, Neumayer et al., found in a randomized, controlled study that laparoscopic repair resulted in significantly more recurrences at 2 years $(10.1 \%$ vs. $4.9 \%)$ and was associated with more complications (39\% vs. $33.4 \%$ ) including more life-threatening complications ( $1.1 \%$ vs. $0.1 \%)$ ) 211 .
In 2019a cohort study in Scotland by Ramsay and his colleagues on 88,590 patients, there were 10,145 LHR and 78,445 OHR. Recurrent operations were required in $1397(1.8 \%)$ OHR and 362 (3.6\%) [22].

There may be a component of experience involved, as surgeons who have performed a high volume of hernia operations appear to have better results. In another study published in the Lancet, all seven hernia recurrences occurred in the laparoscopic group while there were no recurrences in the open repair group $(1.9 \%$ vs. $0.0 \%, p=0.017)$ [19].

In addition, a 2003 meta-analysis comparing laparoscopic and open repair demonstrated a trend toward more short-term recurrences with laparoscopic repair although the results were not statistically significant [15].

When treating recurrent hernias, there may be a difference. In one review, laparoscopic repair of inguinal hernias was found to have a similar recurrence to open repair $(10.0 \%$ vs. $14.1 \%)$. Thus, although there is no clear consensus in the literature, there may be a marginal benefit in terms of recurrence for open versus laparoscopic surgery [19].

Recurrence rates were higher among patients whose hernias were repaired by the laparoscopic technique. There was significant interaction between the surgical approach and the type of hernia ( primary or recurrent). Recurrence rates were significantly higher after laparoscopic repair of primary hernias than after open repair of primary hernias, but recurrence rates associated with the two techniques were similar for the repair of recurrent hernias [21].

In five studies concerning the treatment of recurrent hernias, the recurrence rate varies between $0.4 \%$ and $8.3 \%$ for laparoscopic techniques and between $1 \%$ and $15.6 \%$ for the Lichtenstein procedure. However, the recurrence rate differs greatly between hospitals and individual surgeons, especially for those that perform laparoscopic procedures. For those that have passed an educational program with specific regard to laparoscopy, the recurrence rate is low.

Vale et al., concluded in 2004 involving 2164 patients in 14 centers in USA measured recurrence of hernia at two years as the primary outcome. Recurrence was found to be $10.1 \%$ in the laparoscopic group and $4.1 \%$ for open group in the repair of nrimary inouinal hernias hut ratec of recurrence 
were similar in two groups after repair of recurrent hernias (10\% and $14.1 \%$ respectively) [23].

MRC laparoscopic hernia trial group found 1. 9\% recurrence rate in laparoscopic group and zero percent recurrence rates in open group at one year this was reported in the study of Jain et al., [ 14], this study involved 928 patients with inguinal hernias from 26 hospitals in UK and Ireland [14].

Also, in the study of Champault et al., [24] found recurrence rate of $6 \%$ in laparoscopic group versus $2 \%$ in open group in a series of 100 patients in a randomized trial.

Incidence of complications is significantly higher in laparoscopic group $(0.8 \%)$ versus $(0.2 \%)$ in open group $(p<0.001)$. Incidence of vascular and visceral injuries was found to be higher after laparoscopic repair $(0.79 \%$ after lap repair versus $0 \%$ after open repair in NICE paper). IN MRC hernia trial group, all serious complications occurred in the laparoscopic group. In Vale trial, ( 2004), complication rate was $39.1 \%$ in lap group including 2 deaths but $33.4 \%$ in open group [23].

In an extensive review by Cochrane group in conjunction with European Hernia trialist group [ 21], found serious vascular and visceral injuries more often in laparoscopic group (visceral injuries 8: 2315 and vascular injuries 7:2498). A higher rate of post-operative urinary retention was found in the TEP group $(6.3 \%)$ than in the open group (1. $7 \%)$. This complication was successfully managed by urinary catheterization during the night.

In a randomized controlled trial by Vidovic and his colleagues in a meta-analysis by Schmidt et al., in 2005 involving 34 trials the incidence of urinary bladder injuries in laparoscopic repairs was significantly higher at $0.1 \%$ versus zero after open mesh repairs. Also, the overall incidence of vascular injury during laparoscopic repairs was 0 . $09 \%$ as against no reported cases during open operations [25].

Post-operative pain is another important outcome to consider when choosing between laparoscopic and open repair of inguinal hernias. Most of studies used the visual analogue scale (VAS) for pain measurement. The VAS is a straight line, usually $100 \mathrm{~mm}$ in length, with the left end of the line representing no pain and the right end of the line representing the worst pain. Patients are asked to mark on the line where they think their pain is. The VAS is thought to be more sensitive than using categorical ratings.
Laparoscopic repair has been associated with less post-operative pain than open repair. A 2003 Cochrane Database Systematic Review demonstrated less persisting pain, and less persisting numbness in the laparoscopic groups. Similarly, another metaanalysis study from the EU Hernia Trialists Collaboration reported decreased post-operative pain with the employment of laparoscopic methods [20].

Post-operative pain was found to be less in laparoscopic hernia repair group across the board. Vale and his colleagues in their study did not find any difference in post-operative pain after 14 days [ 23]. Stoker et al., found less post-operative pain for the first 4 hours after open hernia repair probably due to effect of local anesthesia [14]. The proportion of patients with reported testicular pain was higher in the TEP group ( $p=.003)$ in a study reported by Hallan and his coworkers in a randomized control trial comparing TEP with open mesh inguinal repair [26].

In a randomized controlled study by Pawanindra Lal and his colleagues found that the TEP repair was significantly less painful than the open repair at $12 \mathrm{~h}$ and $24 \mathrm{~h}: 2.64 \pm 1.4$ and $1.76 \pm 1.4$ versus $3.52 \pm 1.7$ and $2.74 \pm 1.5$, respectively. The Visual Analog Scale (VAS) pain score at $48 \mathrm{~h}$ and $72 \mathrm{~h}$ in TEP group were less than in the open group ( $p=0.06$ ). On day 7 , there was no significant difference in VAS score between the two groups: $0.36 \pm 0.75$ versus $0.60 \pm 0.95$. The mean analgesic intake in the TEP group was significantly less than in the open group [27].

The post-operative pain can further be reduced with the help of newer analgesic techniques like TAPP block, peri-portal infiltration of bupivacaine and advances in fixation devices like glue and selfretaining meshes [17].

There was marked heterogeneity in length of hospital stay, with greater differences in mean stay between different hospitals than there were between laparoscopic and open repairs in the same hospital. In respect of between trial group differences, the trials tended to show either no difference or a clear difference, sometimes in exact days. This suggests that the overall finding of shorter stay after laparoscopic repair reflects hospital policy rather than a true effect of the repair [20].

In Murthy study, the mean post-operative hospital stay was 2.6 days for laparoscopic hernia repair group, whereas it was 6.1 days for Open Lichtenstein's repair. Hence the mean post-operative hospital stay was significantly less in laparoscopic repair than open hernia repair with $p<0.0001$ which 
was extremely significant. So, from this study it can be concluded that laparoscopic hernia repair is associated with less post-operative hospital stay and better comfort than open hernia repair [17].

On the other hand, post-operative pain is an important determinant of hospital stay and return to work. The mean post-operative hospital stay after TEP repair was 1.48 days (range, 1-2 days). All the patients who underwent TEP repair were fit for discharge within $24 \mathrm{~h}$. The mean hospital stay after open repair was 1.40 days (range, 1-2 days). There was no significant difference in hospital stay between the two groups [27].

Another variable that is used as a primary outcome in numerous studies comparing laparoscopic and open techniques is return to normal activities and work. There is a general consensus in the literature that patients who undergo laparoscopic inguinal hernia repair return to work and normal activities more rapidly than those who undergo open repair [28].

However, there was evidence of statistical heterogeneity and this is likely to be due to differences between trials in: Post-operative advice, definition of usual activity (e.g work, walking, sport), existing co-morbidity, and local cultures. Majority of patients are able to perform normal activities at one week whether after open or laparoscopic surgery. Data regarding time to return to activity are rather subjective. Time to return to daily activities was found to be one day shorter for laparoscopic group than those undergoing open repair of hernia in Vale and his colleagues study [14].

The time to the resumption of sexual activity was similar in the two groups (median time, 14 days in the laparoscopic group and 14 days in the open group). More patients in the laparoscopic group than in the open group were able to perform specific activities (e.g., climbing stairs and engaging in vigorous activities, such as shoveling or weight lifting) at two weeks [21].

Type of employment or profession, to which patient is returning will influence how long he needs to be away from work. Patient who is doing desk job in office will return to work earlier than a patient with a job that entails heavy lifting. Some patients will be getting paid sick leave, so they will have less incentive to go back to work early.

Liem et al., reported that patients who underwent laparoscopic repair resumed normal daily activity 4 days earlier ( 6 days vs. 10 days; $p<0$. 001 ), returned to work 7 days earlier (14 days vs. 21 days; $p<0.001)$ and resumed athletic activities 12 days earlier (24 days vs. 36 days; $p<0.001)$ than those who had open repair. Thus, individual consideration of a patient's work situation can play a role in the decision for laparoscopic or open inguinal hernia repair [19].

In the study of Pawanindra Lal and his colleagues the mean time until return to work was significantly earlier in the TEP group $(12.8 \pm 7.1$ days) than in the open group $(19.3 \pm 4.3 ; p<0$. 001)

[27].

According to Technology appraisal guidance Published in 2004, there were fewer cases of persistent pain at 1 year post-operation after laparoscopic repair, compared with open repair, in both TAPP and TEP studies.

A meta-analysis published in the British Journal of Surgery in 2010 used chronic pain as a primary outcome and found no significant difference between the laparoscopic and open cohorts [29]. However, these results differ from many other reports including the 2003 Cochrane Database Systematic Review, which reported less persisting pain in the laparoscopic groups [19]. Similar results were reported by Eklund et al., in 2010, a comparison of open and laparoscopic repair found that 5 years post-operatively, $1.9 \%$ of patients who had undergone laparoscopic repair continued to report moderate or severe pain compared with $3.5 \%$ of those in the open repair group [30].

Bignell and his colleagues reported a similar higher incidence in chronic groin pain in open versus laparoscopic inguinal hernia repair. However, the decrease in chronic groin pain with laparoscopic repair reported in this study did not translate into a significant improvement in the quality of life [31].

In 2004, a paper by NICE concluded that laparoscopic inguinal repairs was associated with an increased cost of between 100-400 sterling pounds per procedure. Open pre-peritoneal method was found to be most cost effective method of open repair. Hospital stay was shortest with this method of repair. Laparoscopic hernia repair in UK has additional cost of 300 pounds over open repair, because of more operating time, time in hospital and use of specialized equipments and obligatory need for general anaesthesia. The argument that the additional cost of lap hernia is offset by can earlier return of activity has been questioned [14].

Another analysis concluded that laparoscopic renair vxac not rect offertive in terme of roct nor 
recurrence avoided. In a study by Jacobs which compared institutional costs in laparoscopic TEP versus open repair of inguinal hernia, procedure related cost to the hospital was found to be higher for laparoscopic repair in comparison to open repair but still laparoscopic repair was economical to hospital because of higher rate of reimbursement for laparoscopic repair by insurance companies [32].

Laparoscopic inguinal hernia repair is a more complex procedure with a steeper learning curve than open repair. It requires different skills and a familiarity with preperitoneal anatomy. Two large series concluded that 250-300 cases are required to achieve expertise. Jacobs in his study suggested that laparoscopic hernia repair should only be carried out in specialist centers [32]. All most all studies have concluded that laparoscopic hernia repair should be carried out by a surgeon who has a specialized training in performing this procedure [ 14].

Quality of life measured in terms of postoperative pain, quick return to normal activity physical role, general health \& emotional role was found to be significantly better in TEP repair in comparison to open mesh repair in the published randomized control trial by Myers et al., [33].

In De Jonge et al., review of the literature published in 2008 this study reviews the existing literature examining chronic pain and HealthRelated Quality of Life (HRQL) outcomes in hernia repair. The majority of studies used the Visual Analogue Scale (VAS) for pain measurement and the Medical Outcomes Study Short-Form 36 (SF36) for the measurement of HRQL and concluded that the HRQL domains most often affected by pain (social functioning/mental health). The prevalence of chronic pain and discomfort following IHR vary widely between studies. This is probably a reflection of the range of methods used for measuring pain, many of which do not have established psychometric properties. And that review suggests that a proportion of patients experience chronic pain and discomfort, which has a significant impact on HRQL. However, the current instruments used in the evaluation of chronic pain after IHR are not comparable and standardization is required [34].

The SF-36 questionnaire is a standardized procedure for the assessment of health-related quality of life developed from the RAND Corporation Medical Outcomes Study (RAND Health, Santa Monica, CA, USA) which analyzes 8 domains of quality of life: Body function, satisfaction of body and emotional roles, social function, pain, psychological status, vitality as well as individual perception of the patient's global health.

Till date no clear cut scientific data is there in published literature which reflects incidence / etiology of sexual dysfunction after groin hernia surgery. However in some of the patients it may be purely psychic or due to chronic inguinodynia they may experience some difficulty in sexual intercourse [14].

In the retrospective study included 216 patients operated for inguinal hernia in 2006 using tension free mesh repair procedures: Lichtenstein or laparoscopy (TAPP) procedure, the quality of life analysis of the operated patients, using short form questionnaire (SF-36) There were no statistically significant differences between the patients operated with Lichtenstein's procedure and the patients operated with laparoscopic procedure (TAPP) in any of eight categories analyzed with SF-36 questionnaire. The results were slightly better for laparoscopy. These patients had better physical functioning, less post-operative fatigue and loss of energy, less pain and better general health but without statistically significant differences compare to Lichtenstein's repair [35].

\section{Conclusion:}

Laparoscopic hernia repair is more costly; difficult to learn with a steep learning curve, our results provide evidence that after a laparoscopic repair return to usual activity is faster and persisting pain is reduced. However, operation times are longer and there appears to be a higher rate of serious complication rate in respect of visceral and vascular injuries. The complication rate reduces as the surgeons become more experienced in this procedure comparable with that of open repair. Laparoscopic repair is associated with less postoperative morbidity and faster recovery and satisfaction as documented by less post-operative pain, earlier mobilization and discharge from the hospital, as well as early return to work.

Open mesh repair is economical, easy to teach and learn without any steep learning curve. Open hernia repair does not need any specialized training and results are same in both specialist and nonspecialist center. Open hernia repair does not carry any risk of serious visceral or bowel injuries. Open inguinal hernia repair is ideal for day-care surgery, especially under local anesthesia. The final word on management of inguinal hernia is still to be written. Our data support the concept of individu- 
alizing hernia repair for the best results and cost effectiveness.

\section{References}

1- WILLIAMS L.S. and HOPPER P.D.: Understanding Medical-Surgical Nursing, 5th ed.; F.A. Davis: Philadelphia, PA, USA, 2015; p. 7, 2015.

2- HENIFORD B.T.: Hernia Handbook, 1st ed.; Carolinas HealthCare System: Charlotte, NC, USA, 2015.

3- BAYLÓN K., CAMARILLO P.R., ZÚÑUIGA A.E., ELIZONDO J.A.D., GILKERSON R. and LOZANO K.: Past, Present and Fture of Surgical Meshes: A Review. Membranes, 7: 47-69, 2017.

4- JANSEN P.L., MERTENS P.R., KLINGE U. and SCHUMPELICK V.: The biology of hernia formation. Surgery, 136 (1): 1-4, 2004.

5- HENRIKSEN N.A., JENSEN K.K. and JORGENSEN L. N.: The biology of hernia formation. In Textbook of Hernia (pp. 1-5). Springer, Cham, 2017.

6- ZÖLLER B., JI J., SUNDQUIST J. and SUNDQUIST K.: Shared and nonshared familial susceptibility to surgically treated inguinal hernia, femoral hernia, incisional hernia, epigastric hernia, and umbilical hernia. Journal of the American College of Surgeons, 217 (2): 289-99, 2013.

7- HENRIKSEN N.A., HELGSTRAND F., VOGT K.C., JORGENSEN L.N., BISGAARD T. and DATABASE D. H.: Risk factors for incisional hernia repair after aortic reconstructive surgery in a nationwide study. Journal of Vascular Surgery, 57 (6): 1524-30, 2013.

8- BURCHARTH J., POMMERGAARD H.C. and ROSENBERG J.: The inheritance of groin hernia: A systematic review. Hernia, 17 (2): 183-9, 2013.

9- WAGH P.V., LEVERICH A.P., SUN C.N., WHITE H.J. and READ R.C.: Direct inguinal herniation in men: A disease of collagen. Journal of Surgical Research, 17 (6): 425-33, 1974.

10- SZCZESNY W., GLOWACKA K., MARSZALEK A., GUMANSKI R., SZMYTKOWSKI J. and DABROWIECKI S.: The ultrastructure of the fascia lata in hernia patients and healthy controls. Journal of Surgical Research, 172 (1): e33-e7, 2012.

11- HENRIKSEN N.A., MORTENSEN J.H., SORENSEN L.T., BAY-JENSEN A.C., ÅGREN M.S., JORGENSEN L.N. and KARSDAL M.A.: The collagen turnover profile is altered in patients with inguinal and incisional hernia. Surgery, 157 (2): 312-21, 2015.

12- HENRIKSEN N.A., MORTENSEN J.H., LORENTZEN L., ÅGREN M.S., BAY-JENSEN A.C., JORGENSEN L.N. and KARSDAL M.A.: Abdominal wall hernias-A local manifestation of systemically impaired quality of the extracellular matrix. Surgery, 160 (1): 220-7, 2016.

13- HOPE W.W., COBB W.S., ADRALES G.L. (Eds.): Textbook of hernia. Springer International Publishing, 2017.

14- JAIN S.K., GUPTA A., KUMAR S. and KAZA R.C.M.: Laparoscopic vs. open inguinal hernia repair: A systematic review of literature. Asian J. Med. Sci., 5 (3): 10-4, 2014.
15- MEMON M.A., COOPER N.J., MEMON B., MEMON M.I. and ABRAMS K.R.: Meta-analysis of randomized clinical trials comparing open and laparoscopic inguinal hernia repair. Br. J. Surg., 90 (12): 1479-92, 2003.

16- BRINGMAN S., RAMEL S., HEIKKINEN T., ENGLUND T., WESTMAN B., ANDERBERG B., et al.: Tension free inguinal hernia repair. TEP versus mesh plug versus Lichtenstein (a prospective randomized clinical trial). Ann. Surg., 237: 142-7, 2003.

17- MURTHY P.K. and RAVALIA D.: Assessment and comparison of laparoscopic hernia repair versus open hernia: A non-randomized study. International Surgery Journal, 5 (3): 1021-5, 2018.

18- SMINK D.S., PAQUETTE I.M., FINLAYSON S.R.: Utilization of laparoscopic and open inguinal hernia repair: A population-based analysis. J. Laparoendosc. Adv. Surg. Tech. A, 19 (6): 745-8, 2009.

19- KAVIC S.M.: Laparoscopic versus open repair: A superior approach to inguinal herniorrhaphy. OA Minimally Invasive Surgery, 1 (1): 1, 2013.

20- McCORMACK K., SCOTT N., GO P.M., ROSS S.J. and GRANT A.: Laparoscopic techniques versus open techniques for inguinal hernia repair. Cochrane database of systematic reviews, (1), 2003.

21- NEUMAYER L., GIOBBIE-HURDER A., JONASSON O., FITZGIBBONS R., DUNLOP D., GIBBS J., et al.: Open mesh versus laparoscopic mesh repair of inguinal hernia. N. Engl. J. Med., 350 (18): 1819-27, 2004.

22- RAMSAY G., SCOTT N.W. and JANSEN J.O.: A 19 year population-based cohort study analysing reoperation for recurrence following laparoscopic and open inguinal hernia repairs. Hernia, 1-8, 2019.

23- VALE L., GRANT A., McCORMACK K. and SCOTT N. W.: EU Hernia trialist collaboration. Cost effectiveness of alternative methods of surgical repair of inguinal hernia. Int. J. Technol. Assess. Health Care, 20: 192-200, 2004.

24- CHAMPAULT G., RIZK N., CATHELINE J.M., BARRAT C., TURNER R. and BOUTELIER P.: Inguinal hernia repair. Hernia, 1 (1): 31-6, 1997.

25- VIDOVIC D., KIRAC I., GLAVAN E., CUGURA F.J., LEDINSKY M. and BESLIN B.M.: Laparoscopic Totally Extraperitoneal Hernia Repair Versus Open Lichtenstein Hernia Repair: Results and Complications. J. Lap. \& Ad Surg. Techniques, 17: 585-90, 2007.

26- HALLAN M., BERGENFELZ A. and WESTERDAHL J.: Laparoscopic extraperitoneal inguinal hernia repair versus open mesh repair: Long-term follow-up of a randomized controlled trial. Surgery, 143 (3): 313-7, 2008.

27- LAL P., KAJLA R.K., CHANDER J., SAHA R. and RAMTEKE V.K.: Randomized controlled study of laparoscopic total extraperitoneal versus open Lichtenstein inguinal hernia repair. Surgical Endoscopy, 17 (6): 850, 2003.

28- WALL M.L., CHERIAN T. and LOTZ J.C.: Laparoscopic hernia repair: The best option? Acta Chir. Belg., 108 (2): 186-91, 2008.

29- KARTHIKESALINGAM A., MARKAR S.R., HOLT P.J. and PRASEEDOM R.K.: Meta-analysis of randomized controlled trials comparing laparoscopic with open mesh 
repair of recurrent inguinal hernia. Br. J. Surg., 97 (1): 4-11, 2010.

30- EKLUND A., MONTGOMERY A., BERGKVIST L. and RUDBERG C.: Swedish Multicentre Trial of Inguinal Hernia Repair by Laparoscopy (SMIL) study group: Chronic pain 5 years after randomized comparison of laparoscopic and lichtenstein inguinal hernia repair. $\mathrm{Br}$. J. Surg., 97 (4): 600-8, 2010.

31- BIGNELL M., PARTRIDGE G., MAHON D. and RHODES M.: Prospective randomized trial of laparoscopic ( transabdominal preperitoneal-TAPP) versus open (mesh) repair for bilateral and recurrent inguinal hernia: Incidence of chronic groin pain and impact on quality of life: Results of 10 year follow-up. Hernia, 16 (6): 63540, 2012.

32- JACOBS V.R. and MORRISON J.E.: Comparison of institutional costs for laparoscopic pre-peritoneal inguinal ambulatory surgery center. Surg. Laparosc. Endosc. Percutan Tech., 18 (1): 70-4, 2008.

33- MYERS E., BROWENE K.M. and KAVANAGH D.O.: Laparoscopic (TEP) Versus Lichtenstein Inguinal Hernia Repair: A Comparison of Quality of Life Outcomes. WorldJ. Surg., 34 (12): 3059-64, 2010.

34- De JONGE P.V.H., LLOYD A., HORSFALL L., TAN R. and O'DWYER P.J.: The measurement of chronic pain and health-related quality of life following inguinal hernia repair: A review of the literature. Hernia, 12 (6): 561-9, 2008.

35-SR SLEN D., DRǓZIJANIC' N., POGORELIC' Z., PERKOZ. , JURICIC' J., KRALJEVIC' D. and MIMICA Z Z: Quality of life analysis after open and laparoscopic inguinal hernia repair: Retrospective study. Hepato-gastroenterology, 55 ( 88): 2112-5, 2008.

\section{مقارنة بين إصلاح الفتق الإربى بالمنظار والفتح الجراحى الفت الإنى}

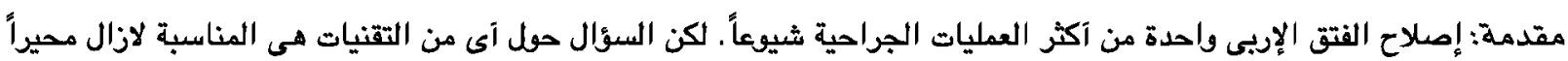

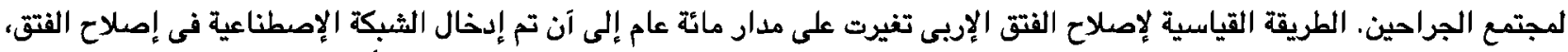

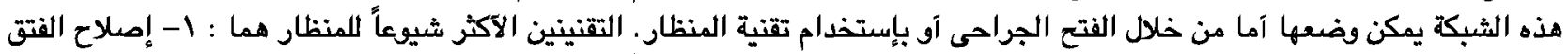

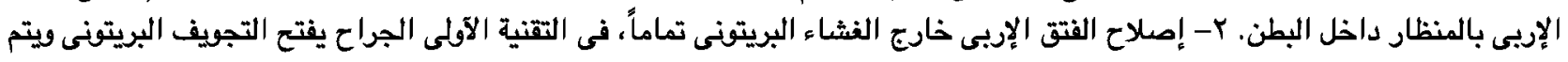

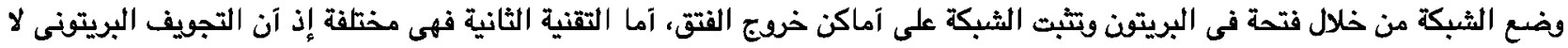

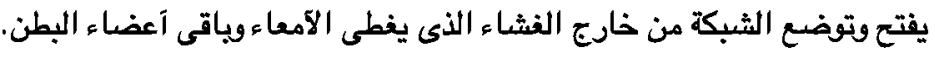

$$
\text { الهدف من البحث: كان الغرض من هذه المراجعة مقارنة بين إصلاح الفتق الإربى بالمنظار والفتح الجراحى مع إستخدام شبكة. }
$$

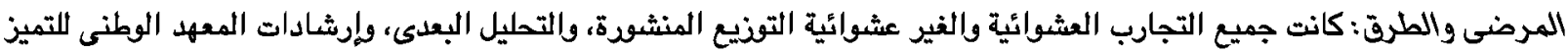

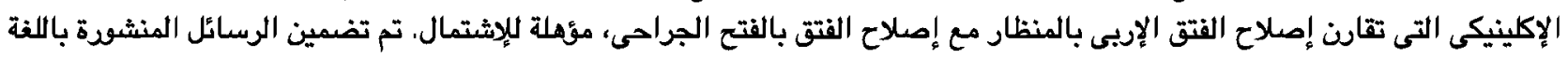

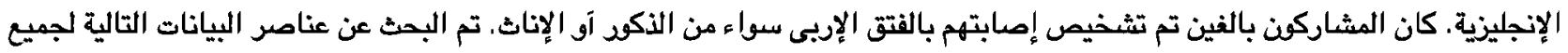

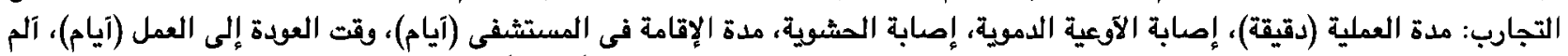

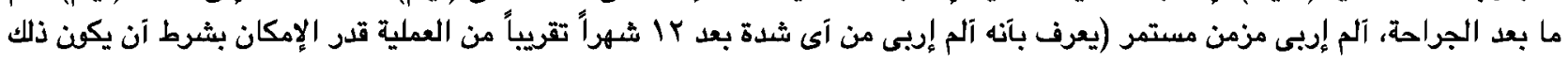

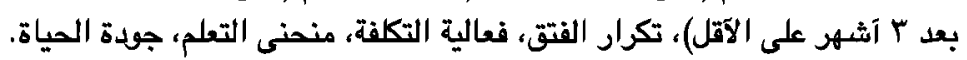

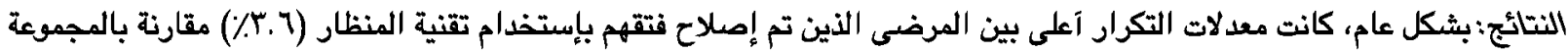

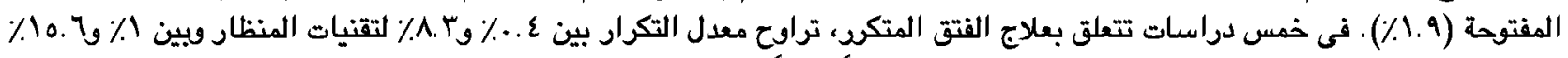

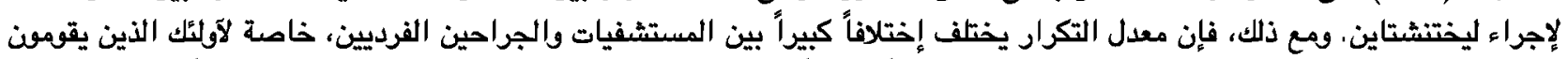

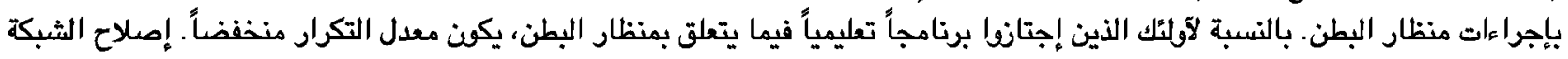

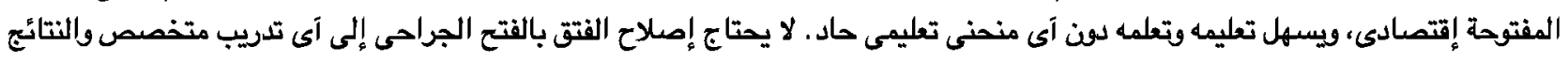

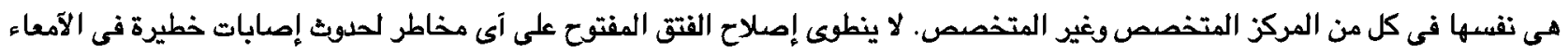

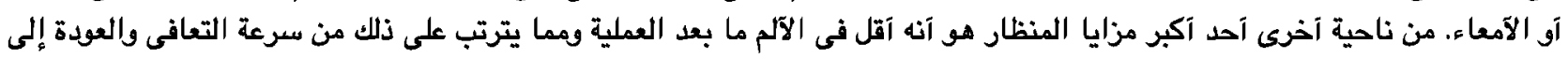

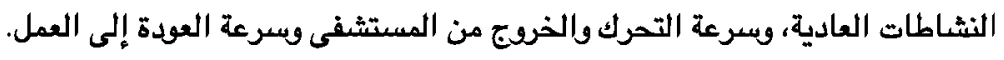

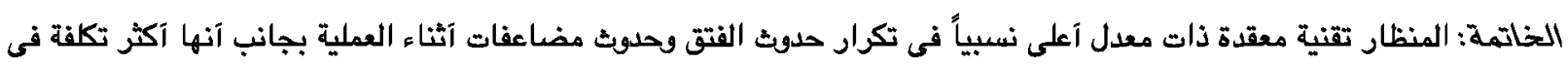

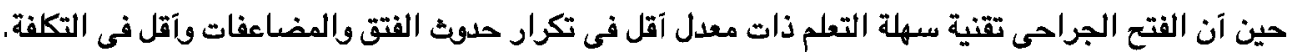

